\title{
Primary management of fracture of femoral neck in young adults using Valgus Osteotomy and fixation with Dynamic hip screw and plate: A case series.
}

\author{
${ }^{1}$ Tapadiya Dwarkadas G, ${ }^{2}$ Thete Sandesh S, ${ }^{3}$ Deshmukh Gajanan K \\ ${ }^{I} M S$ (orthopedics) Professor and Head of department, DUPMCH, Jalgaon \\ ${ }^{2} \mathrm{MS}$ (orthopedics) Assistant Professor, DUPMCH, Jalgaon \\ ${ }^{3}$ Senior Resident, DUPMCH, Jalgaon
}

\begin{abstract}
:
Background: Fracture neck femur in young patients continues to be a difficult problem to treat even for the most experienced. In-spite of the advances made in Orthopedics this fracture remains an unsolved problem. Various treatment modalities and their modifications have been proposed to improve the outcome of treatment. Osteosynthesis and primary valgus angulation osteotomy is one of them. Technique and outcome in a series of recent intracapsular femoral neck fractures in young adults is presented.

Materials and Methods: Ten patients of recent ( $<3$ weeks old) displaced intracapsular fracture neck femur (Garden III and IV, Pauwels III, with or without comminution) in the age group 20-40 years (mean 27.5 ) were subjected to osteosynthesis and primary valgus intertrochanteric osteotomy using dynamic hip screw with side plate and a derotation screw. The patients were followed up from three to five years (mean 4.6 years).

Results: Union at the fracture site was achieved in ten out of ten (100\%) patients within 12 months of surgery. One case, which had undergone previous surgery with multiple screw fixation, developed avascular necrosis(10\%). Repeat surgery rate was 10\% (for patient with AVN) however, none of the patients required repeat surgery for achieving union. None of the ten patients had poor outcome. All patients can sit cross legged and squat and are back to their previous jobs.

Conclusion: The DHS method is economical and readily available. It produces satisfactory results employing a device and instrumentation that is more familiar to orthopedic surgeons. The technique is reproducible and has been used successfully in this series of 10 patients.
\end{abstract}

Key words: Fracture neck femur, young adult,valgus osteotomy,DHS.

\section{Introduction}

Intracapsular femoral neck fractures are commonly seen in the elderly population after a trivial fall. ${ }^{1}$ Femoral neck fractures in adults younger than age 50 years are uncommon, accounting for only $2-3 \%$ of all femoral neck fractures ${ }^{2,3}$, and are often the result of high-energy trauma. ${ }^{2,4}$ In the new era of joint replacement surgeries this problem is solved in older individuals where expected life span is less than life of endoprosthesis. But in younger patients whose life span is more than life of endoprosthesis and who require high level activity and squatting in their daily life style, belonging mainly to lower socio economic strata of society, physiological hip joint is better solution than any kind of arthoplasty. Soundly united fracture neck femur is always superior physiologically and functionally to replacement arthoplasty hence, osteosynthesis is indicated in younger patients with fracture neck femur.

Femoral neck fractures in young adults are associated with higher incidences of femoral head osteonecrosis ${ }^{4,6-8}$ and nonunion. ${ }^{4,6,9,10}$

The rate of osteonecrosis reported in the literature ranges from 12-86\% in young patients after femoral neck fracture. ${ }^{4,911-14}$ Unfavorable factors like (a) initial vascular insult (resulting in AVN), (b) posterior comminution and (c) vertical fracture line (enhancing chances of nonunion) are largely beyond the surgeon's control. ${ }^{1,2}$ In an unstable fracture pattern (displaced and/or vertical fracture line and/or comminuted) various treatment modalities and their modifications have been proposed to improve the outcome. Osteosynthesis and primary valgus angulation osteotomy is one of them. ${ }^{3-8}$ The indications and the place of this procedure, in the management of adult recent femoral neck fracture is yet not clearly defined. We present outcome of an easy-toperform, cost-effective technique in a consecutive series of recent intracapsular fracture neck of femur in young adults. This study does not aim to prove or disprove any particular method of treatment but serve to delineate the effectiveness and ease of valgus osteotomy fixed with DHS and side plate in fracture neck femur in young patients. 


\section{Material and Methods}

Ten cases of fracture neck femur having Pauwel's type III fractures were treated primarily by valgus osteotomy during the period 2006 - 2008. All were males who had sustained a road traffic accident. Two patients had additional fractures of upper limb. Age range of patients was $25-40$ yrs. Five cases were fixed within 48 hrs of injury while rest within 2 weeks of injury. Fracture and osteotomy was fixed with Dynamic hip screw and plate and $6.5 \mathrm{~mm}$ concellous screw (derotation screw). These patients were followed up for a minimum period of two years (to look for AVN). Prior approval for this study was obtained from the institutional review committee.

The inclusion criteria were (a) age between 20-50 years (b) traumatic, fresh, closed intracapsular femoral neck fracture of less than three weeks duration (c) Garden Stage III or IV (d) Pauwels Type III fracture line (e) patient able to participate in postoperative rehabilitation program.

The exclusion criteria were (a) pathological fractures (b) patients on oral / injectable steroids (c) clinically detectable major illness like malignancy, chronic renal disease etc. (d) Garden Stage I and II, (e) Pauwels Type I and II, (f) Ipsilateral or contralateral major limb injury affecting treatment and rehabilitation program.

\section{Preoperative Planning ( Figure 1)}

Good quality anterior radiograph of the pelvis with both hips is a must. Draw templates of normal side over paper. Preoperatively one should calculate-

1) Pauwel's Angle - Angle made by distal fracture line with horizontal. In most of cases it was $50-70^{\circ}$.

2) Wedge Angle $=$ Pouwel's angle $-30^{\circ}$

Aim of osteotomy is to decrease Pauwel's angle from $50-70^{\circ}$ to $30^{\circ}$. So the required wedge to achieve this angle is calculated preoperatively by calculating wedge angle. Length of wedge is calculated by making wedge angle at lesser trochanter over a template.

\section{Operative Technique}

After an informed consent patients were taken up for surgery after pre-anesthetic checkup. Under appropriate anesthesia, the patients were taken on the fracture table for closed reduction (Ledbatter's Method). If two attempts at closed reduction failed then open reduction was done. Garden's alignment index was used for assessment of adequacy of reduction ${ }^{1}$. Desired length (approximately $12.5 \mathrm{~cm}$ ) of the lateral cortex of the femur was exposed through lateral/Watson Jones approach. A blunt-tipped Hohman's retractor was passed above the lesser trochanter after palpating it with the finger. This was the guide to the most proximal and medial level of osteotomy. The desired lateral closed wedge osteotomy was marked. Under image intensifier control one guide wire is passed flush to the anterior cortex, away from the tract of final instrumentation, to maintain the reduction. This wire is removed at the end of procedure. Then the guide wire for Richards screw was inserted, aiming for the inferior and central position. At last the guide wire for derotation screw was passed in head. After accessing the adequacy of reduction and position of guide wires under image intensifier, the derotation screw is introduced first. A $6.5 \mathrm{~mm}$ cancellous canulated screw of adequate length is passed over the second guide wire. Then after proper preparation, a Richards screw of adequate length passed over first guide wire. Next the osteotomy is made at level of lesser trochanter. Lateral closing wedge Y osteotomy as preoperatively planned (already discussed in preoperative planning) is made. Wedge of bone is removed. Limb distal to osteotomy site is abducted and DHS plate with sufficient number of screw holes is applied. Angle of plate is decided by preoperative planning. Usually $140^{\circ}-145^{\circ}$ plate required. Bone grafts of wedge may be kept on medial side at osteotomy site. Usually osteotomy site is in between DHS hole of plate and first hole for cortical screw of plate. Distally plate is fixed with $4.5 \mathrm{~mm}$ cortical screws. Rotational alignment should be observed during the procedure of securing the plate. If required two holes should be made prior to osteotomy one above and one below osteotomy site and aligned with each other while applying plate. Wound is closed in layers over a suction drain. The acceptability of reduction was graded on the basis of residual angulation and the amount of displacement as excellent ( $<2 \mathrm{~mm}$ displacement and/or less than $5^{\circ}$ angulation in any plane), good $(2-5 \mathrm{~mm}$ displacement and/or $5-10^{\circ}$ angulation), fair (>5 to $10 \mathrm{~mm}$ of displacement and/or $10-20^{\circ}$ angulation) $)^{9}$ or poor (>10 $\mathrm{mm}$ displacement and/or $>20^{\circ}$ angulation).

\section{Post operative management}

No extra immobilisation is required postoperatively. Antibiotics and analgesics are given for 3 days. Bed side knee exercises started on $3^{\text {rd }}$ day after removal of drain. Non weight bearing crutch ambulation started on $10^{\text {th }}$ day. Pt discharged on $10-12^{\text {th }}$ day after removeal of stitches 
Follow up

After suture removal follow up is done at 6 weeks, 12 weeks, six months and at the end of one year and every year thereafter for five years. At each follow up a check x-ray is done. Nonunion was defined as persistence or increase in fracture gap at six months, sclerosis of fracture margins, loss of reduction or failure of fixation with implant breakage. Patient was assessed for pain, range of movements and lengthing/shortening and gait pattern.

\section{Results (Table 1)}

Excellent reduction could be achieved in 2 patients (20\%), good in $8(80 \%)$ and fair/poor in none. The preoperative mean Pauwels angle of $68 \pm 12^{\circ}$ was converted to a mean of $33 \pm 7^{\circ}$ after valgus osteotomy ( Figure 2 ). The patients were followed up for two to six years (mean 4.6 years). All the fractures $(100 \%)$ had united by six months postoperatively( Figure 3). One patients (10\%) developed AVN (Figure 4). In nine cases osteotomy united by three months. One patient had delayed union at the osteotomy site which took six months to unite. Excellent results were achieved in 7 patients (70\%), good / fair in two (20\%) and poor in one (10\%) by Harris Hip Score. ${ }^{10}$ One patient developed AVN of head of femur. Limp was present in 3 patients and lengthening of about $1 \mathrm{~cm}$ in 2 patients. None of the patients required secondary procedures like, debridement, implant removal, girdlestone excision arthroplasty, hemiarthroplasty, muscle pedicle bone grafting and pelvic support osteotomy. Only one patient required total hip replacement for AVN. No implant-related complication like pullout of screws or breakage of plate occurred in this study.

\section{Discussion}

Fracture neck femur in young patients is unsolved problem. Unfavorable factors like (a) initial vascular insult (resulting in AVN), (b) posterior comminution and (c) vertical fracture line (enhancing chances of nonunion) are largely beyond the surgeon's control. ${ }^{5,15}$ In an unstable fracture pattern (displaced and/or vertical fracture line and/or comminuted) various treatment modalities and their modifications have been proposed to improve the outcome. Osteosynthesis and primary valgus angulation osteotomy is one of them. ${ }^{16,17}$

Osteosynthesis is treatment of choice. Various modalities to supplement osteosynthesis have been reported in literature. These include 1) Valgus Osteotomy 2) Muscle Pedicle graft ${ }^{18}$ 3) fibular Graft (Vascular / Non Vascular) ${ }^{19}$

For most femoral neck fractures, the recommended fixation technique is with multiple cancellous lag screws. The Pauwels' Type I and II, but not Type III, are most amenable to this type of fixation.

In Pauwels' Type III fracture, the dominant shear force that is seen with this high-angle fracture pattern lends itself to a higher rate of failure and nonunion. ${ }^{20-23}$. The valgus osteotomy addresses this issue by reducing the postreduction Pauwels angle. The role of concomitant valgus osteotomy and internal fixation of fresh femoral neck fractures have been reported in the literature. ${ }^{24-26} \mathrm{~A}$ valgus osteotomy converts the shear force to compressive forces at the fracture site. This increases the stability of the implant and allows for faster healing. However, many authors use Pauwels classification to treat femoral neck delayed and nonunion and not acute fracture. ${ }^{1}$ A postreduction type III Pauwels may be predictive of the outcome. ${ }^{1}$ More recently Magu et al. ${ }^{24}$ reported their outcome on 50 adult patients with osteoporosis who underwent a primary valgus intertrochanteric osteotomy for displaced femoral neck fracture. The interval between injury and surgery ranged from three to 30 days (no mean reported). They concluded that this is a dependable procedure for fresh fractures of femoral neck with osteoporosis. Different authors in different studies shown $70-100 \%$ union rates. Mach et al. reported $80 \%$ excellent to good results. Fontanesi C reported $71 \%$ excellent to good results in study of 24 patients with one nonunion and 4 AVN. Potalo F had reported $100 \%$ union rate with $15 \%$ AVN in his study of 26 patient. Studies of Huang C.H. and Rinaldi reports $81-89 \%$ excellent to good results. ${ }^{27,28}$

Several biomechanical studies ${ }^{29,30}$ have evaluated different implants for managing Pauwels' Type III femoral neck fractures. Baitner et al. ${ }^{29}$ compared multiple screws to the DHS for treatment of Pauwels' Type III femoral neck fracture. They found that the DHS had less inferior femoral head displacement, less shearing displacement and a greater load to failure when compared to the three cannulated cancellous screws. Bonnaire and Weber $^{30}$ looked at four different methods of fixation (DHS with derotational screw, DHS without derotational screw, cancellous screws and a 130 degrees angled blade plate) for Pauwels' Type III cadaveric femoral neck fractures. They concluded that the DHS with the derotational screw is the best implant for this fracture pattern.

Of these Pauwel's Y osteotomy appears to be more effective, Princple of this osteotomy is conversion of shearing forces into compressive forces at fracture site by horizontalisation of fracture line. ${ }^{24,28,31}$

In our study there is $100 \%$ union rate with $10 \%$ of AVN rate with no infection or implant failure. To conclude, Valgus osteotomy and internal fixation is better option for treatment of Pauwel's type II and type III fractures in young patients. If little preoperative planning is done result are encouraging. 
Acknowledgements-Nil

Conflicts of interests-Nil.

Table 1: Demographics and characteristics of evaluated cases

\begin{tabular}{|c|c|c|c|c|}
\hline Characteristics & Number & $\%$ & Osteonecrosis & $\%$ \\
\hline \multicolumn{5}{|l|}{ Sex } \\
\hline Male & 10 & 100 & 1 & 100 \\
\hline Female & - & - & - & - \\
\hline \multicolumn{5}{|l|}{ Age group } \\
\hline $10-20$ & 1 & 10 & - & - \\
\hline $20-30$ & 6 & 60 & - & - \\
\hline $30-40$ & 3 & 30 & 1 & 33 \\
\hline \multicolumn{5}{|l|}{ Garden grade } \\
\hline II & 3 & 30 & - & - \\
\hline III & 4 & 40 & - & - \\
\hline IV & 3 & 30 & - & - \\
\hline \multicolumn{5}{|l|}{ Time of surgery } \\
\hline$<24$ hours & 2 & 20 & - & - \\
\hline $24-72$ hours & 2 & 20 & - & - \\
\hline$>72$ hours & 6 & 60 & 1 & 16.25 \\
\hline \multicolumn{5}{|l|}{ Reduction } \\
\hline Excellent & 7 & 70 & - & - \\
\hline Good & 2 & 20 & 1 & \\
\hline Poor & 1 & 10 & - & - \\
\hline
\end{tabular}

[1]. Christodoulou NA, Dretakis EK. Significance of muscular disturbances in the localization of fractures of the proximal femur. Clin Orthop Relat Res.1984;187:215-7

[2]. Robinson CM, Court-Brown CM, McQueen MM, Christie J. Hip fractures in adults younger than 50 years of age: Epidemiology and Results. Clin Orthop Relat Res. 1995;312:238-46

[3]. Zetterberg CH, Elmerson S, Andersson GB. Epidemiology of hip fractures in Goteborg, Sweden, 1940-1983. Clin Orthop Relat Res. 1984;191:43-52,

[4]. .Protzman RR, Burkhalter WE. Femoral-neck fractures in young adults. J Bone Joint Surg Am. 1976;58:689-95.

[5]. Leighton RK. Fractures of the neck of femur. In: Bucholz RW, Heckman JD, Court-Brown C, editors. Rockwood and Green's fractures in adults. 6th ed. vol. 2. Philadelphia: Lippincott Williams and Wilkins; 2006. pp. 1753-91.

[6]. Dedrick DK, Mackenzie JR, Burney RE. Complications of femoral neck fracture in young adults. J Trauma. 1986;26:932-7.

[7]. Haidukewych GJ, Rothwell WS, Jacofsky DJ, Torchia ME, Berry DJ. Operative treatment of femoral neck fractures in patients between the ages of fifteen and fifty years. J Bone Joint Surg Am. 2004;86:1711-6.

[8]. Zetterberg CH, Irstam L, Andersson GB. Femoral neck fractures in young adults. Acta Orthop Scand. 1982;53:427-35.

[9]. Kofoed H. Femoral neck fractures in young adults. Injury. 1982;14:146-50.

[10]. Shih CH, Wang KC. Femoral neck fractures. Clin Orthop Relat Res.1989;271:195-200.

[11]. Askin SR, Bryan R. Femoral neck fractures in young adults. Clin Orthop Relat Res. 1976;114:259-64.

[12]. Swiontkowski MF, Winquist RA, Hansen ST. Fractures of the femoral neck in patients between the ages of twelve and forty-nine years. J Bone Joint Surg Am.1984;66:837-46

[13]. Gautam VK, Anand S, Dhaon BK. Management of displaced femoral neck fractures in young adults (a group at risk) Injury. 1998;29:215-8.

[14]. Upadhyay A, Jain P, Mishra P, Maini L, Gautum VK, Dhaon BK. Delayed internal fixation of fractures of the neck of the femur in young adults. J Bone Joint Surg Br. 2004;86:1035-40

[15]. Scheck M. The significance of posterior comminution in femoral neck fracture. Clin Orthop Relat Res. 1980;152:138-42.

[16]. Bado JL. Experience in treatment of intracapsular fracture of neck of femur. J Bone Joint Surg Am. 1948;30:294-302.

[17]. Blounts WP, Wisconsin M. Blade plate internal fixation for high femoral osteotomies.J Bone Joint Surg. 1943;25:319-39.

[18]. Meyers MH, Harvey JP Jr, Moore TM. The muscle pedicle bone graft in the treatment placed fractures of the femoral neck: indications, operative technique and results. Orthop Clin North Am 1974; 5: 779-792.

[19]. Nagi ON, Gautam VK, Marya SK. Treatment of femoral neck fractures with a cancellous screws and fibular graft. J Bone joint Surg (Br). 1986; 68: 387-391.

[20]. Bartonickek J. Pauwels' classification of femoral neck fractures: Correct interpretation of the original. J Orthop Trauma. 2001;15:358-60.

[21]. Stankewich CJ, Chapman J, Muthusamy R, Quaid G, Schemitsch E, Tencer AF, et al. Relationship of mechanical factors to the strength of proximal femur fractures fixed with cancellous screws. J Orthop Trauma. 1996;10:248-57.

[22]. Vercruysse R, Fourneau I, Driesen R, Stappaerts KH. Unstable femoral neck fractures in young adults: Treatment with the AO 130degree blade plate. J Orthop Trauma. 1998;12:235-9.

[23]. Weinrobe M, Stankewich CJ, Mueller B, Tencer AF. Predicting the mechanical outcome of femoral neck fractures fixed with cancellous screws: An in vivo study. J Orthop Trauma. 1998;12:27-37.

[24]. Magu NK, Singh R, Mittal R, et al. Osteosynthesis and primary valgus intertrochanteric osteotomy in displaced intracapsular fracture neck of femur with osteoporosis in adults. Injury. 2005;36:110-22.

[25]. Mishra US. Intertrochanteric displacement osteotomy in the treatment of femoral neck fractures. Injury. 1979;10:183-9.

[26]. Fontanesi G, Costa P, Giancecchi F, Tartaglia I. Intertrochanteric valgus osteotomy and sliding compression hip screw in fractures of the femoral neck. Ital J Orthop Traumatol. 1991;17:293-304.

[27]. Huang CH. Treatment of neglected femoral neck fractures in young adults. Clin Orthop. 1986; $206: 117-126$.

[28]. Rinaldi E, Marenghi P, Negri V. Osteosynthesis with valgus osteotomy in the primary treatment of subcapital fractures of the neck of the femur. Ital J Orthop Traumatol. 1984:10:313-320. 
Primary management of fracture of femoral neck in young adults using Valgus Osteotomy .....

[29]. Baitner AC, Maurer SG, Hickey DG, Jazrawi LM, Kummer FJ, Jamal J, et al. Vertical shear fractures of the femoral neck. Clin Orthop Relat Res.1999;367:300-5.

[30]. Bonnaire FA, Weber AT. Analysis of fracture gap changes, dynamic and static stability of different osteosynthetic procedures in the femoral neck. Injury.2002;33:C24-32.

[31]. Magu NK, Singh R, Sharma A, et al. Treatment of pathological femoral neck fractures with modified Pauwels' osteotomy. Cling Orthop. 2005; 437: 229-235.
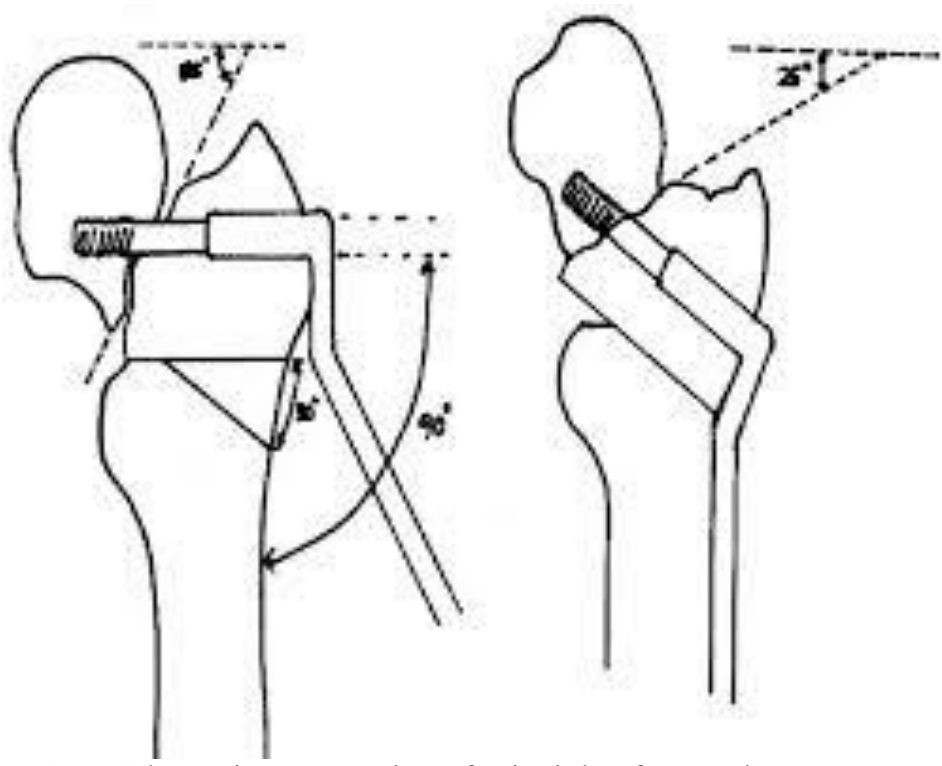

Figure 1. - Schematic presentation of principle of Pauwel's osteotomy.

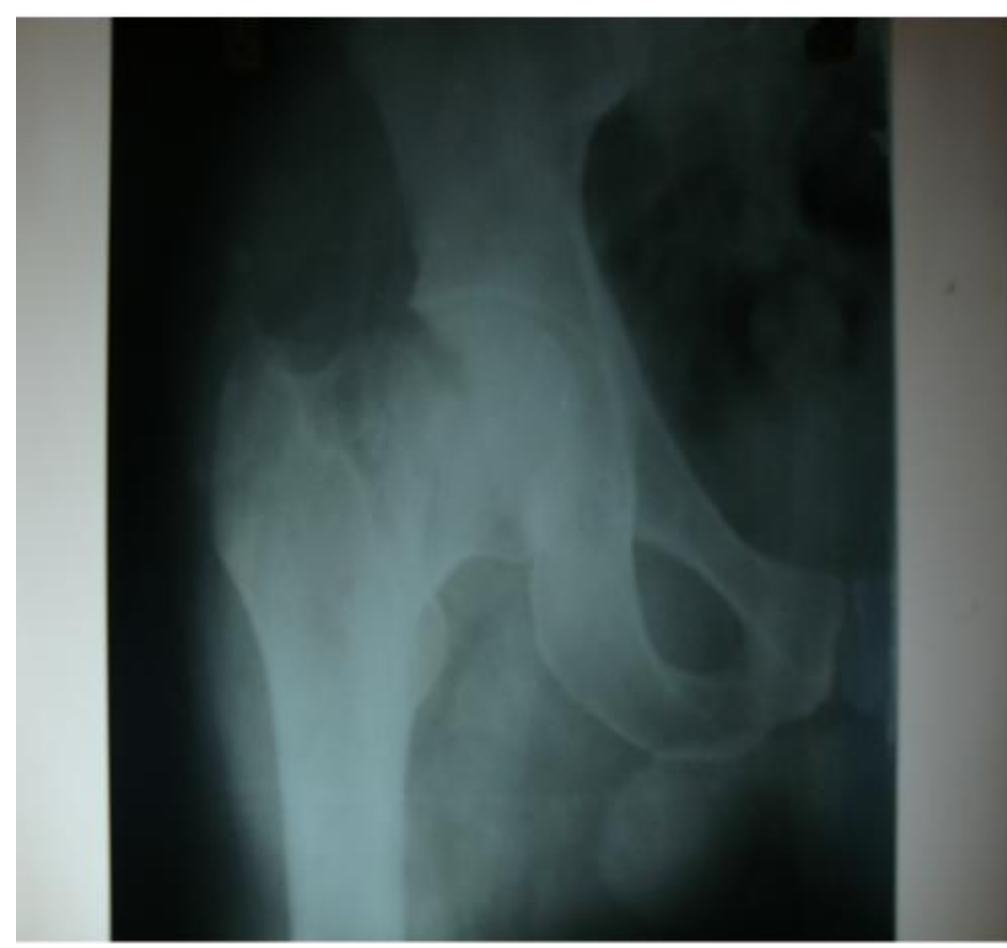

Figure 2(a) 


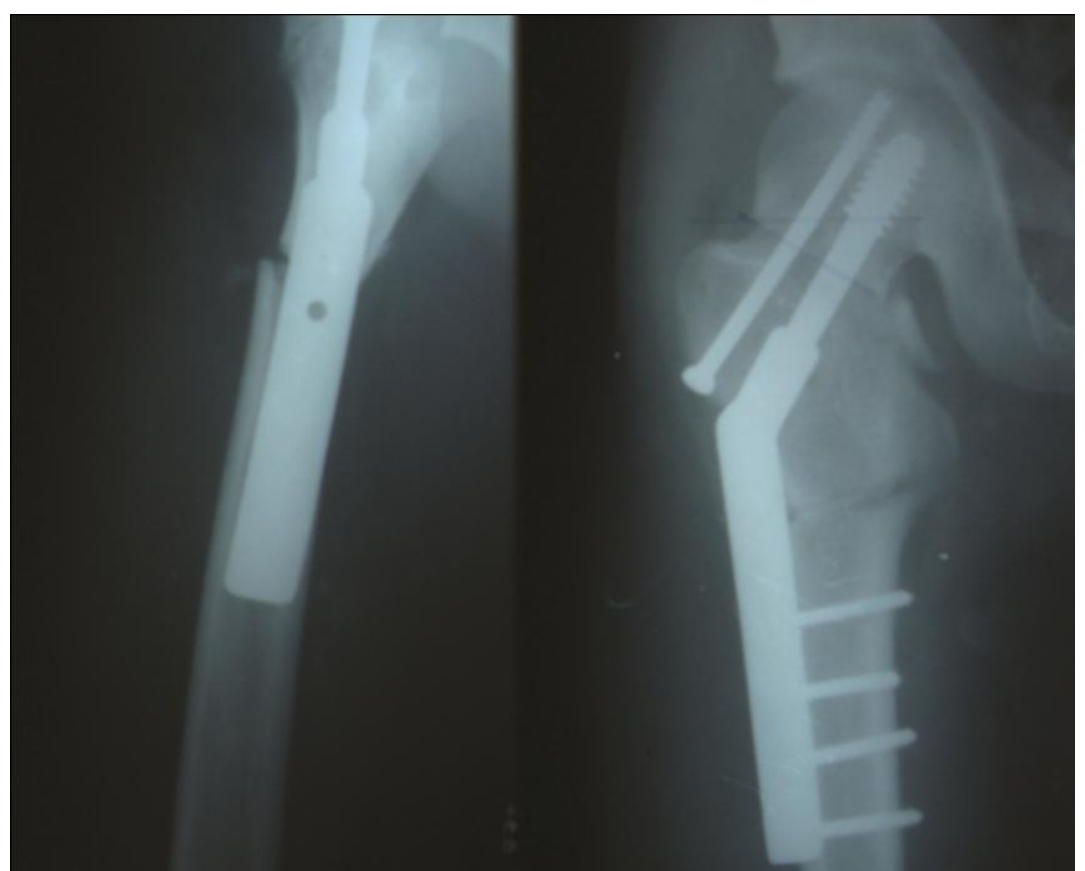

Figure 2 (b) Figure 2 (a \&b) - Pre-operative and immediate post operative radiographs of a patient, showing conversion of Pauwel's angle to $30^{\circ}$ with excellent reduction at fracture site and well placed prosthesis.

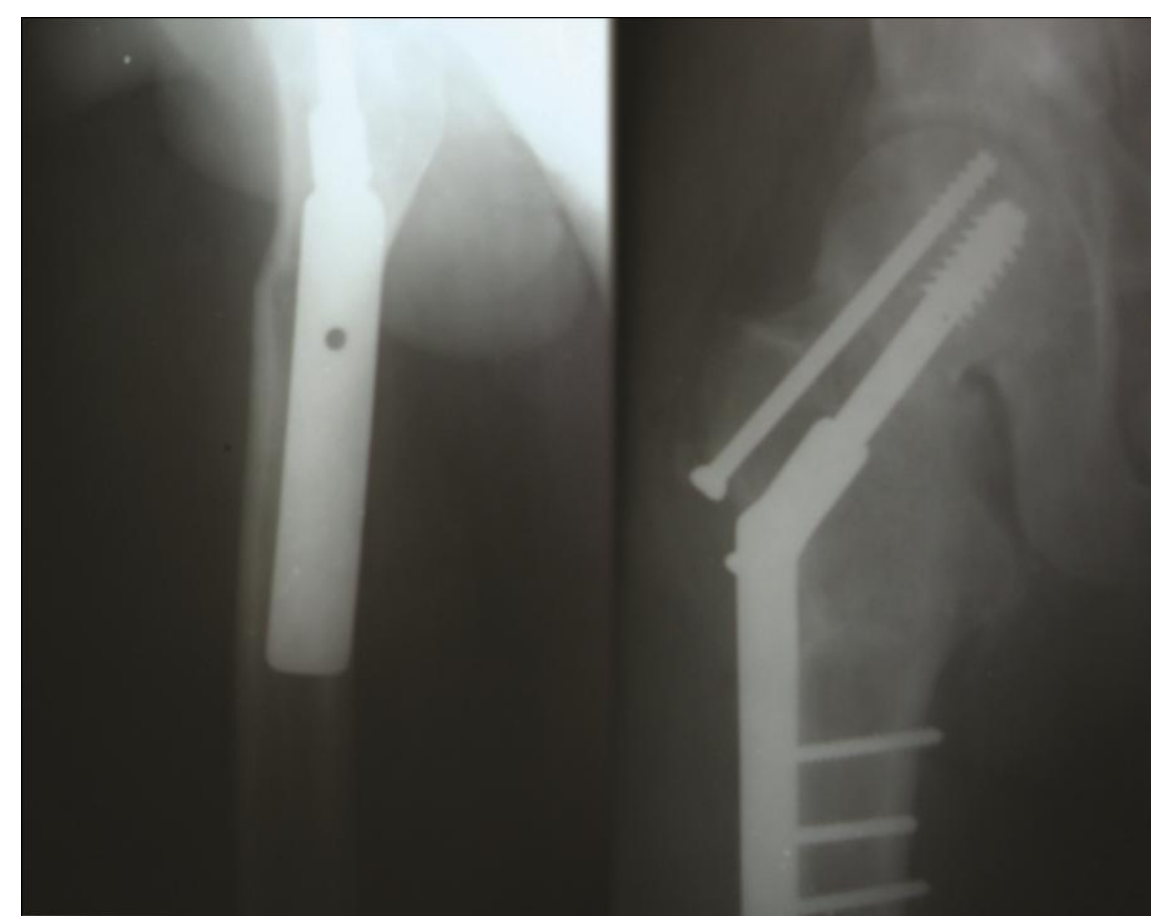

Figure -3 - Radiographs of the same patient at 3 month follow up showing union at the fracture site. 


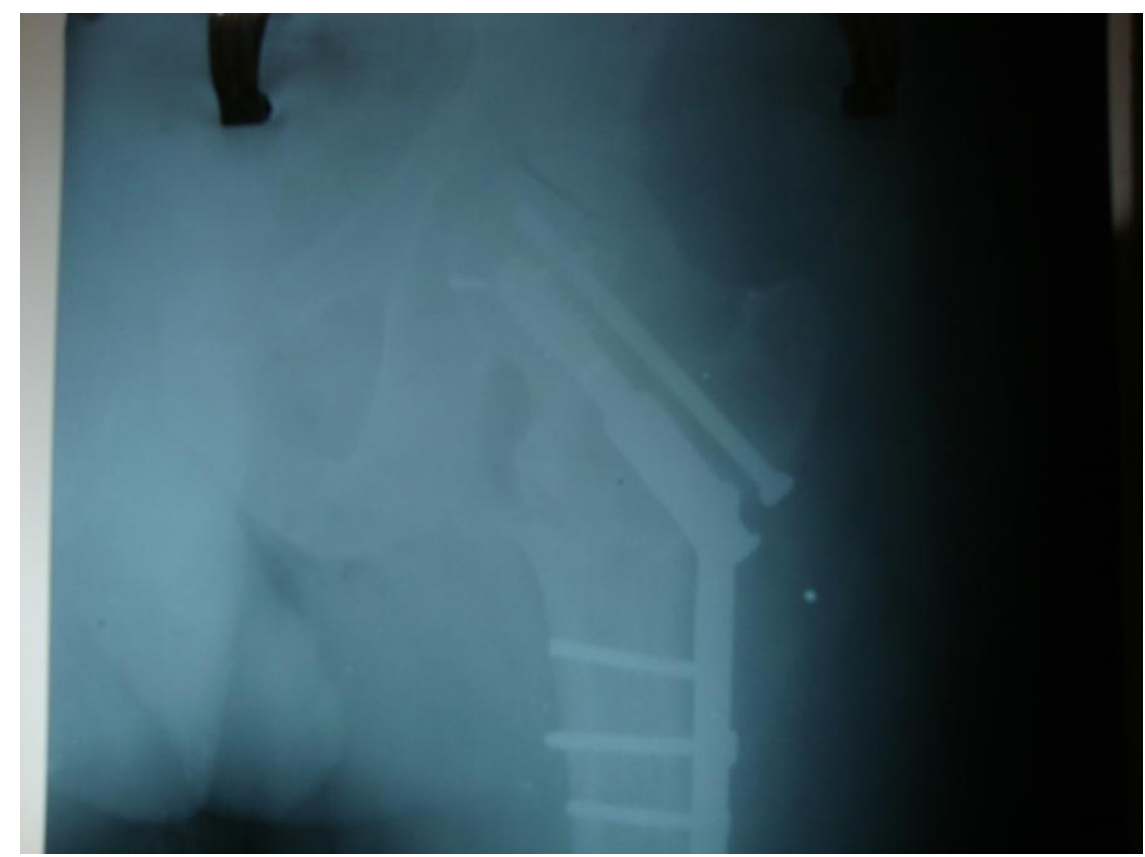

Figure 4 (a)

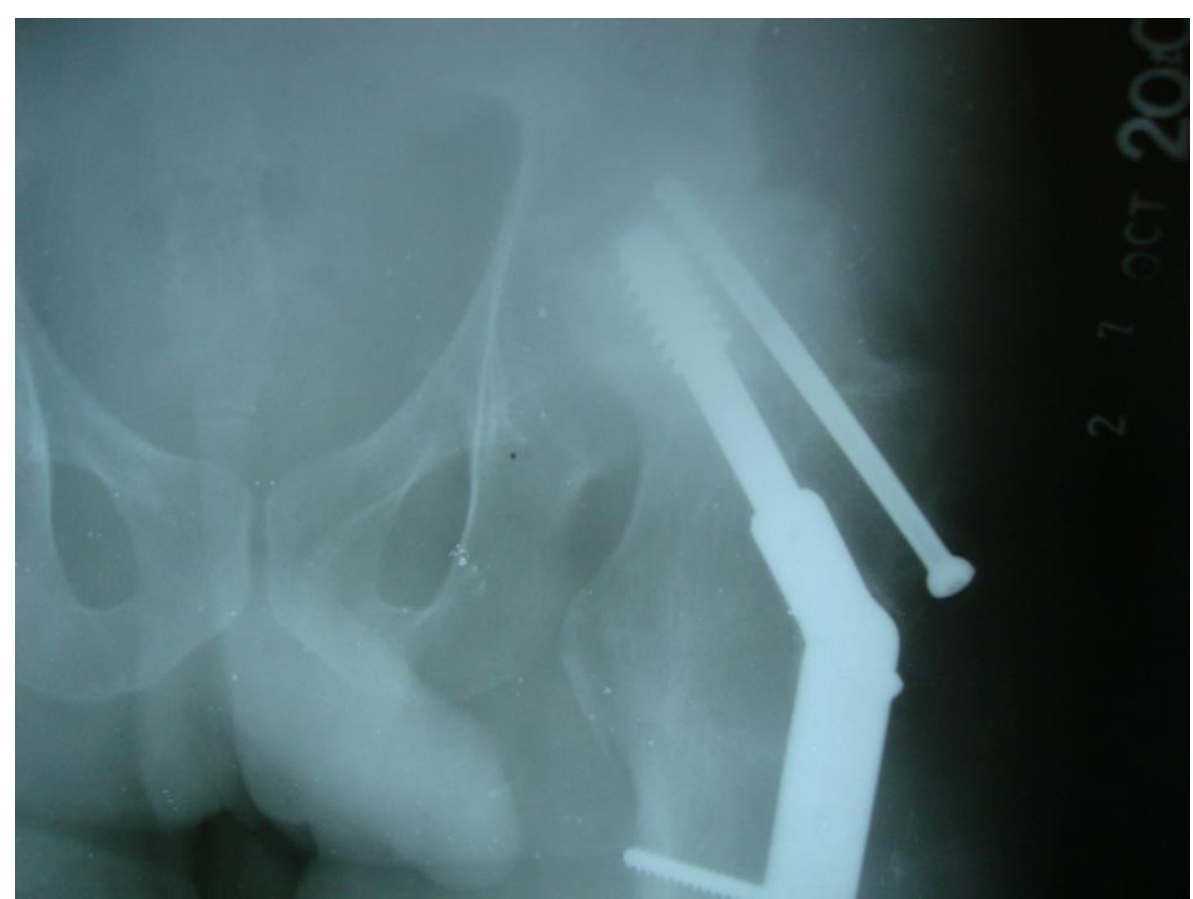

Figure 4(b)

Figure 4( a \& b) - (a) Radiographs of a patient at six months follow up showing union at fracture site and osteotomy site. (b) 12 months follow up radiograph of same patient showing avascular necrosis of head of femur. 